\title{
MALFORMACIÓN ADENOMATOIDEA QUÍSTICA PULMO- NAR DE PRESENTACIÓN TARDÍA: REVISIÓN DEL TEMA Y PRESENTACIÓN DE UN CASO
}

\author{
Drs. Freddy Escobar $L^{(1,2)}$, Francisca Fuentes $D^{(2)}$, Camila Urzúa $F^{(2)}$, María Capetillo $F^{(3)}$.
}

1. Servicio de Radiología, Clínica Vespucio. Santiago, Chile.

2. Servicio de Diagnóstico por Imágenes, Hospital Militar de Santiago. Chile.

3. Servicio Anatomía Patológica, Clínica Vespucio. Santiago, Chile.

REVIEW AND CASE REPORT: LATE-ONSET CONGENITAL CYSTIC ADENOMATOID MALFORMATION OF THE LUNG

\begin{abstract}
The congenital cystic adenomatoid malformation (CCAM) of the lungs is a rare congenital abnormality that it is usually discovered during childhood. Late-onset CCAM is extremely uncommon, usually detected as a radiographic finding in adult patients. Timely diagnosis of this condition is important mainly because of the risk of recurrent infections and mainly for its neoplastic potential. The case of an adult patient is presented.

Keywords: Congenital cystic adenomatoid malformation (CCAM), Lung developmental abnormality.
\end{abstract}

Resumen: La malformación adenomatoídea quística pulmonar es una extraña anomalía congénita que frecuentemente se detecta durante la infancia. La presentación tardía es poco frecuente y más comúnmente se detecta como un hallazgo radiológico en adultos. El diagnóstico de esta patología es importante, principalmente por el riesgo de infecciones recurrentes y transformación neoplásica.

Palabras clave: Anomalía del desarrollo pulmonar, Malformación adenomatoidea quística.

\section{Introducción}

La malformación adenomatoidea quística (MAQ) es una anomalía poco frecuente del desarrollo pulmonar de tipo hamartomatoso, caracterizada por proliferación y dilatación anormal de las estructuras respiratorias terminales, que dan origen a quistes de variados tamaños y localización ${ }^{(1)}$. Constituye

Escobar F. Malformación adenomatoidea quística pulmonar de presentación tardía: Revisión del tema y presentación de un caso. Rev Chil Radiol 2010; 16 (4): 190-194.

Correspondencia: Dra. Francisca Fuentes del Pozo. franfuentesd@gmail.com

Trabajo recibido el 06 de noviembre de 2009, aceptado para publicación el 10 de agosto de 2010. el $25 \%$ del total de malformaciones congénitas del pulmón ${ }^{(2,3)}$. La gran mayoría (85\%) se diagnostican en los dos primeros años de vida por distres respiratorio o infecciones a repetición ${ }^{(4)}$. La presentación en la edad adulta es poco frecuente, diagnosticándose a partir de un hallazgo imaginológico, como lesiones cavitadas en la radiografía de tórax, o en relación a infecciones pulmonares recurrentes.

\section{Caso clínico}

Paciente de sexo masculino de 18 años, sin antecedentes mórbidos de importancia, consulta por cuadro de una semana de tos no productiva y sensación febril. En el contexto epidemiológico de la epidemia de influenza AH1N1 se deja tratamiento empírico con Oseltamivir. Finalizado el tratamiento, el paciente persiste con tos seca por lo que se solicita radiografía $(\mathrm{Rx})$ de tórax que muestra extenso foco de condensación en lóbulo superior izquierdo, asociado a múltiples imágenes cistoídeas que generan efecto de masa sobre el plano cisural (Figura 1). Se solicita tomografía computada (TC) de tórax con contraste, evidenciándose una masa sólido-quística de $13 \mathrm{~cm}$ en el segmento superior del lóbulo inferior izquierdo, el cual se encuentra abombado y ejerce efecto de masa sobre el pulmón adyacente (Figura 2). En su interior se identifican múltiples quistes, los mayores de hasta $23 \mathrm{~mm}$, algunos de ellos con contenido líquido y otros con niveles hidroaéreos. Tras la administración de medio de contraste, el componente sólido de la masa presenta realce homogéneo, sin identificar estructuras vasculares anómalas en su espesor ni vasos aberrantes de origen aórtico. El parénquima pulmonar restante es normal y los hallazgos descritos son sugerentes de malformación adenomatoídea quística sobreinfectada. El paciente es hospitalizado, y recibe tratamiento antibiótico endovenoso por 10 días. Posteriormente se realiza extirpación de la lesión mediante videotoracotomía, realizando segmentectomía superior del lóbulo inferior izquierdo sin incidentes (Figura 3); luego de un post- 
operatorio satisfactorio, es dado de alta. El estudio histopatológico diferido evidencia tejido pulmonar con bronquíolos y alvéolos dilatados, revestidos por epitelio cilíndrico y cuboidal ciliado y simple respectivamente. Sus lúmenes se encuentran ocupados por material mucoide, hemático y exudado fibrinoleucocitario. El estroma está compuesto por tejido fibroconectivo vascularizado y muscular liso, con extensas zonas de necrosis y hemorragia, compatibles con MAQ tipo Il con inflamación aguda secundaria.
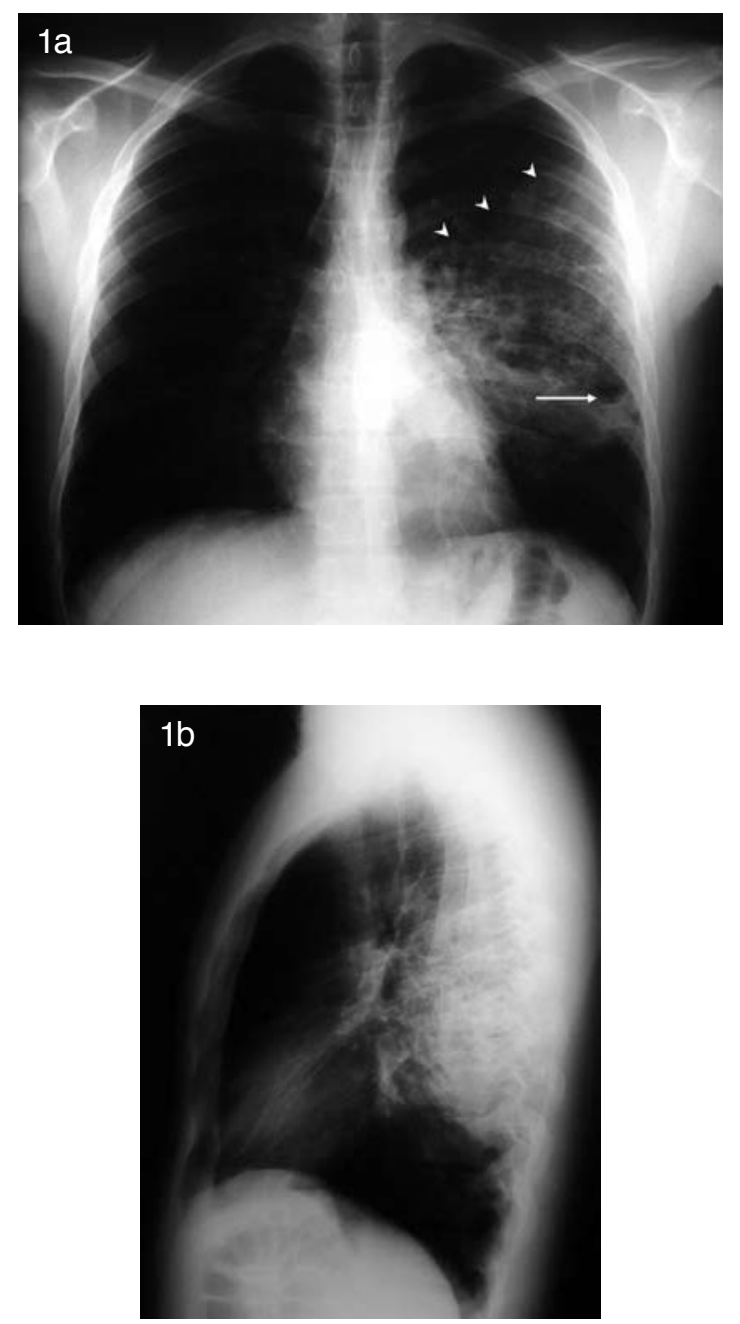

Figura 1. Rx tórax: a) AP. b) L, evidencian imagen de condensación en el tercio medio del hemitórax izquierdo (puntas de flecha), en cuyo interior se identifican múltiples imágenes cistoídeas, una de ellas con nivel hidroaéreo (flecha).

Figura 2. TC de tórax: a) Axial ventana pulmón. b) De mediastino. c) Reconstrucción coronal. d) Sagital; evidencia masa sólido-quística en el segmento superior del lóbulo inferior izquierdo, que ejerce efecto de masa al parénquima adyacente (puntas de flecha). En su interior se identifican múltiples quistes, algunos Ilenos de líquido(flecha negra), otros con niveles hidroaéreos (flecha blanca).
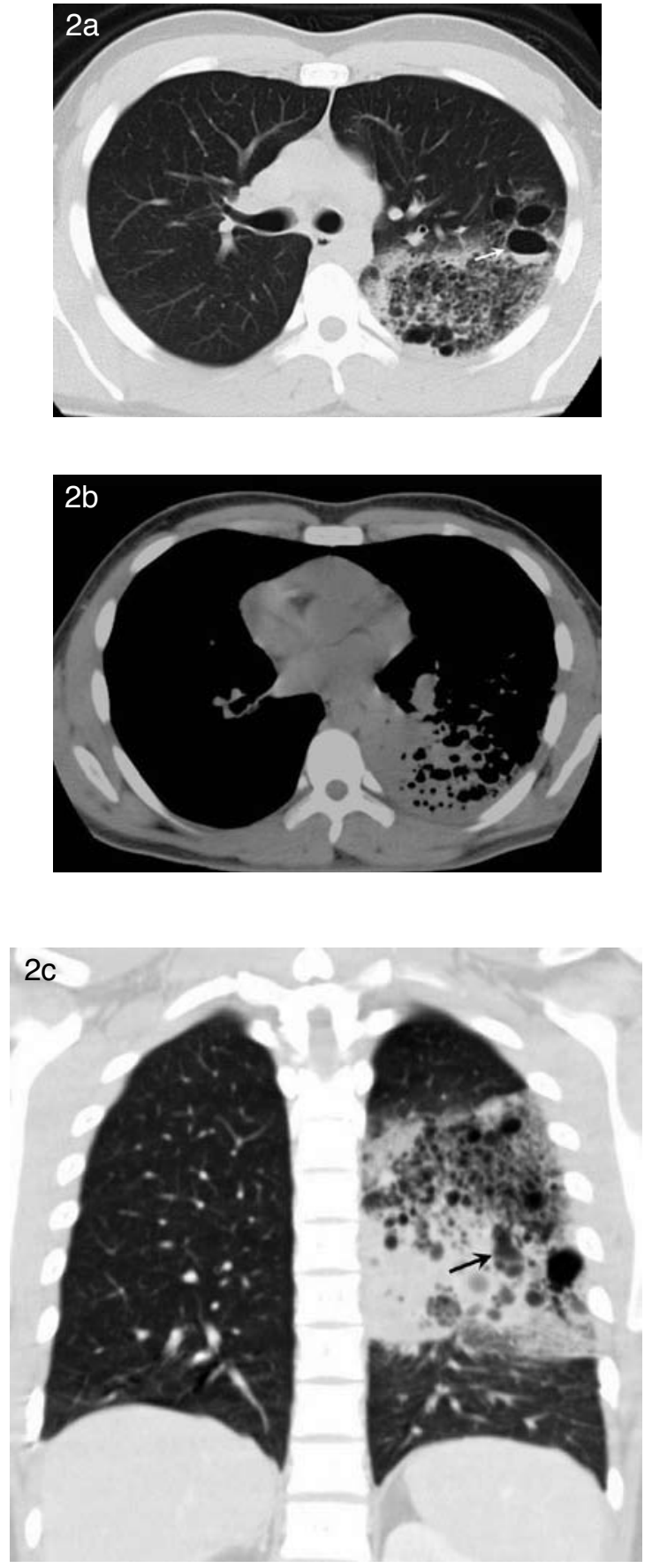

×
号
안

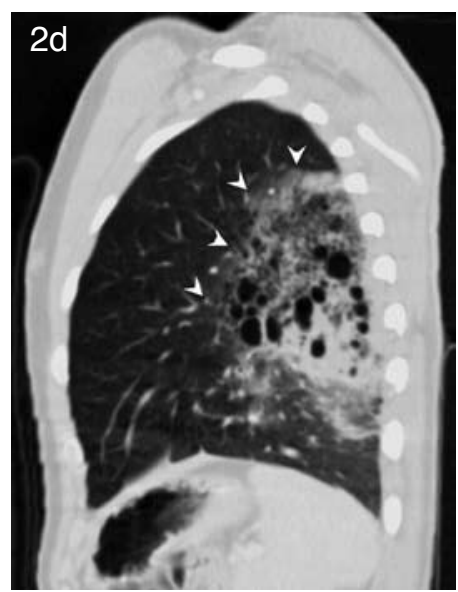




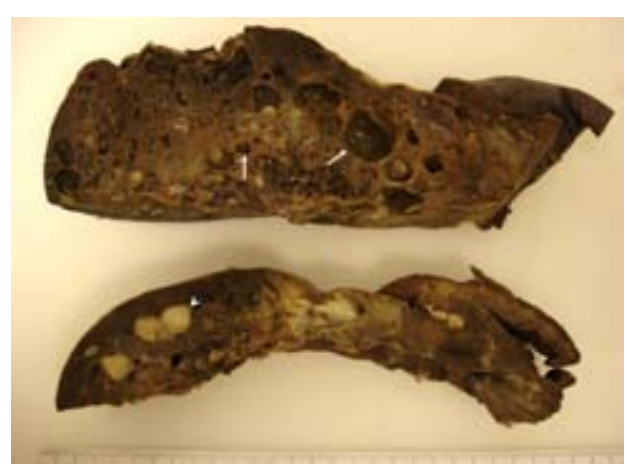

Figura 3. Pieza quirúrgica de segmentectomía. Destacan múltiples estructuras quísticas, algunas de ellas de gran tamaño (flecha) y otras llenas de sustancia mucoídea (punta de flecha).

\section{Clasificación histopatológica}

Esta alteración del desarrollo pulmonar fue descrita inicialmente por Ch 'in y Tang en 1949, quienes observaron ciertas masas pulmonares de apariencia sólida pseudoglandular en mortinatos y recién nacidos prematuros con hidrops. En 1977 Stocker et al., las clasificó de acuerdo a sus características histológicas, en tres tipos ${ }^{(1,2)}$ :

- Tipo I, la más frecuente $(60-70 \%)^{(5)}$, compuesta por uno o más quistes de $2 \mathrm{~cm}$ o más, revestidos por epitelio columnar pseudoestratificado ciliado, rodeado por tejido elástico, bandas de músculo liso, tejido conectivo fibrovascular y cartílago. Además presentan alvéolos de características normales entre las estructuras quísticas.

- Tipo II, formada por múltiples quistes de tamaño uniforme, menores a $2 \mathrm{~cm}$, que remedan bronquíolos terminales entre estructuras similares a alvéolos de gran tamaño. Constan de una pared de epitelio columnar o cuboideo rodeado por una delgada capa fibromuscular y raramente tienen cartílago. Constituye el 20 a $30 \%$ de los casos; en un $50 \%$ se asocia a secuestro pulmonar extralobar ${ }^{(1)}$.

- Tipo III, corresponde al 10\% de los casos ${ }^{(1,5)}$. Constituye una masa sólida voluminosa, compuesta por estructuras milimétricas similares a bronquíolos, separadas por masas de estructuras de tipo alveolares de epitelio cuboidal.

Los distintos tipos descritos pueden coexistir en un mismo paciente. Aunque la clasificación no tiene implicancia en el manejo es importante conocerla para entender su correlación con los hallazgos a la TC.

A la macroscopía, las lesiones pueden ser sólidas, quísticas o sólido-quísticas. Frecuentemente afectan un lóbulo, se comunican con el árbol traqueobronquial y se encuentran irrigadas por la circulación pulmonar. Las lesiones de gran tamaño se asocian a hipoplasia de lóbulos pulmonares ipsi o contralaterales. No se ha descrito predilección por un sitio del parénquima pulmonar en especial.

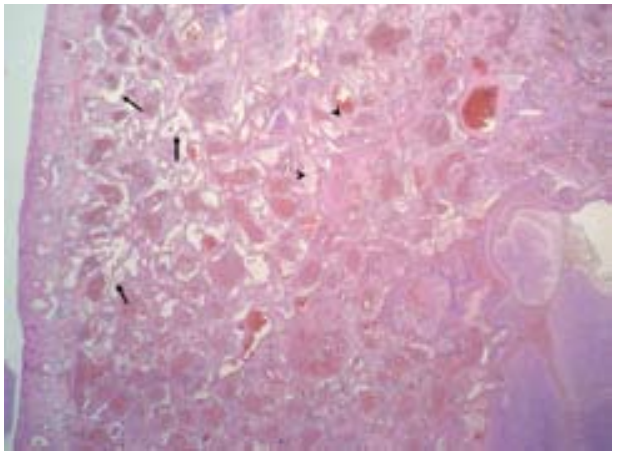

Figura 4. Biopsia: MAQ tipo II. Corte histológico evidencia múltiples imágenes quísticas que remedan alvéolos (flechas), algunos de ellos con mucus (punta de flecha) (H\&E 10x).

\section{Patogenia}

La MAQ es una enfermedad no hereditaria esporádica, asociada a síndromes genéticos como trisomía 18 y displasia renal hereditaria; su patogenia aún es desconocida ${ }^{(1,2)}$. Algunas hipótesis refieren que se debe a una falla en la interacción del endodermo con el mesodermo, a una falla en la irrigación o que podría deberse a un desequilibrio entre la proliferación celular y la apoptosis durante el desarrollo pulmonar.

En el desarrollo del pulmón se identifican cuatro etapas:

- Seudoglandular, hasta la semana 17

- Canalicular, entre las semanas 17 a 24

- Del saco terminal, desde la semana 24 hasta el término de la gestación

- Alveolar, durante el período post-natal.

La MAQ de tipo III se desarrollaría durante el período pseudoglandular y la de tipo II durante el canalicular. La de tipo I no ha sido atribuida a una etapa en particular ${ }^{(1)}$.

\section{Aspectos clinicos}

Frecuentemente se detecta durante la gestación y el período neonatal; el $70 \%$ se confirma en la primera semana de vida y cerca del $90 \%$ se diagnostican durante los dos primeros años de vida ${ }^{(6)}$. Raramente debuta en la adultez; hasta el 2006, en la literatura de habla inglesa se habían reportado cerca de 36 casos en adultos ${ }^{(7)}$.

La MAQ es la causa más frecuente de masa intratorácica fetal diagnosticada por US. Las lesiones más grandes pueden manifestarse durante el embarazo como hidrops, preeclampsia y polihidroamnios ${ }^{(8)}$. Esta malformación podría involucionar hasta desaparecer espontáneamente durante el período intrauterino.

Al nacer se manifiesta como distrés respiratorio, debido a la compresión del parénquima pulmonar normal adyacente a la lesión. Debido a que existe comunicación entre la malformación y el árbol traqueobronquial, se genera hiperinsuflación durante la inspiración y atrapamiento de aire mediante un mecanismo de válvula, determinando un rápido aumento de volumen del pulmón anormal, pudiendo causar falla respiratoria. Al examen físico del 
recién nacido puede haber ausencia de murmullo pulmonar, ruidos cardíacos apagados e hipertimpanismo del hemitórax afectado.

Clínicamente, se considera presentación tardía si la malformación debuta después de los 6 meses de edad. En la infancia se presenta como insuficiencia respiratoria, infecciones pulmonares recurrentes o retardo del crecimiento. La MAQ aparece menos frecuentemente en adolescentes y adultos $(17 \%)^{(1)}$; el paciente permanece asintomático hasta ser diagnosticada incidentalmente mediante $\mathrm{Rx}$ de tórax que detecta lesiones quísticas, 0 bien, como infecciones pulmonares repetitivas, neumotórax espontáneo, hemoptisis o dolor torácico ${ }^{(8)}$.

\section{Hallazgos imaginológicos}

El progreso de la imaginología ha contribuido al adecuado diagnóstico de esta patología; en el pasado, la gammagrafía y la broncografía eran los métodos de estudio. La TC es el estudio de imagen de elección a partir de 1986, ya que permite caracterizar de las lesiones, determinar la extensión del compromiso, describir la anatomía de las estructuras mediastínicas y torácicas adyacentes, además de plantear diagnósticos diferenciales; mediante AngioTC se puede obtener información a cerca de la irrigación arterial. No obstante, puede ser difícil diferenciar la MAQ de otras enfermedades quísticas del pulmón, como el secuestro pulmonar. Los hallazgos imaginológicos son variables dependiendo del tipo, forma de presentación y la edad del paciente al momento de su detección. Mata et al(2), describió tres patrones radiológicos visibles a la TC: quiste único, que puede contener aire o líquido, quistes múltiples y enfisema localizado; los distintos tipos pueden combinarse constituyendo formas de presentación más complejas.

En el ultrasonido (US) obstétrico se puede ver polihidroamnios asociado a una imagen sólida o quística torácica. En la Rx de tórax del recién nacido, lo característico es una imagen multiquística unilateral, que dependiendo de su tamaño puede estar asociada a desplazamiento contralateral del mediastino o condensación ateléctasica de los lóbulos adyacentes; la gran variabilidad morfológica dificulta su diagnóstico con el uso exclusivo de este método de imagen. Otras manifestaciones radiológicas son: gran imagen quística asociada a pequeños quistes periféricos, gran opacidad o imagen compleja sólidoquística. La presencia de nivel hidroaéreo puede deberse a líquido de retención, hemorragia, secreción mucoide o sobreinfección.

Los diagnósticos diferenciales de la MAQ son: hernia diafragmática, quiste broncogénico, hiperinsuflación lobar infantil y secuestro pulmonar ${ }^{(8)}$. EI US puede ayudar en la caracterización de las lesiones.

Si se manifiesta durante el primer año de vida, las lesiones son en general más pequeñas, comprometiendo habitualmente un lóbulo o segmento, aunque puede comprometer el pulmón completo. En el adulto, esta malformación puede simular una neoplasia o evidenciarse asociada a un proceso infeccioso. La ausencia de cartílago en bronquíolos malformados determina el colapso de éstos durante la espiración, quedando secreciones atrapadas hacia distal, lo que predispone a sobreinfección. Esta forma de presentación es radiológicamente indistinguible de una neumonía convencional y debe sospecharse en caso de ausencia de resolución radiológica de la imagen de condensación, a pesar de la mejoría clínica. Los hallazgos a la Rx de tórax son variables, dependiendo de la extensión del compromiso al momento del diagnóstico clínico; algunas lesiones pueden pasar desapercibidas y sólo ser evidentes a la TC.

Las MAQ de tipo I pueden ser confundidas con neumatoceles, o abscesos pulmonares; en estos casos tienden a comprometer más los lóbulos inferiores y puede haber hiperinsuflación del hemitórax ipsilateral, con eventual desplazamiento contralateral del mediastino. Son diagnósticos diferenciales radiológicos en la presentación tardía del adulto: secuestro pulmonar, quiste broncogéni$\mathrm{co}$, bronquiectasias quísticas, enfisema lobar congénito, enfisema localizado, hernia diafragmática, neumonia cavitada, bronquiectasias quísticas, tuberculosis, quiste hidatídico y carcinoma bronquíoloalveolar ${ }^{(2,3)}$.

\section{Pronóstico y manejo}

En caso de diagnóstico intrauterino se puede realizar drenaje de los quistes, con el fin de evitar la hipoplasia de otros segmentos. Van Leeuwen et al. propusieron un manejo conservador de las lesiones pequeñas asintomáticas, con seguimiento imaginológico, ya que no tienden a aumentar de volumen e incluso tienen posibilidad de regresión ${ }^{(1)}$. Sin embargo, no hay evidencia del resultado a largo plazo de este tipo de manejo. Además, el seguimiento idealmente debiera realizarse con TC de alta resolución, con los riesgos que implica la exposición a radiación.

La extirpación quirúrgica es el tratamiento de elección, tanto en pacientes sintomáticos como en los que no, debido al riesgo de transformación maligna, infecciones a repetición y crecimiento de las zonas quísticas, especialmente debido a que los riesgos que conlleva la cirugía son escasos. La técnica quirúrgica depende del tamaño y localización de la lesión; las técnicas más frecuentemente utilizadas son la lobectomía y la segmentectomía ${ }^{(4)}$. Existe tendencia a realizar cirugías con margen de seguridad amplio, ya que resecciones localizadas no anatómicas se relacionan más con recidiva; sin embargo, éstas deben considerarse en caso de masas de gran tamaño o con gran compromiso de la función pulmonar. Resecciones de un $20 \%$ del pulmón en niños determinan una reducción de sólo un $10 \%$ de la capacidad vital forzada (CVF) ${ }^{(1)}$.

En general, el pronóstico es favorable y depende de la extensión, el grado de desarrollo de los segmentos pulmonares adyacentes a la lesión, la asociación con otras malformaciones y la transformación maligna. El seguimiento posterior a la extirpación idealmente debe realizarse con $\mathrm{TC}^{(4)}$, con el objetivo de pesquisar posibles recidivas y malignización. Entre las complicaciones 
asociadas a la MAQ, la transformación neoplásica es la de peor pronóstico (carcinoma bronquíoloalveolar y rabdomiosarcoma) ${ }^{(2)}$, que se asocian especialmente a casos de presentación tardía en niños grandes o adultos jóvenes, por lo que el manejo conservador en pacientes de este rango de edad no estaría justificado. El riesgo de la existencia de tejido remanente no detectado intraoperatoriamente hace recomendable la realización de seguimiento clínico y radiológico a largo plazo(9).

\section{Conclusión}

La MAQ es una anomalía congénita rara, que habitualmente se manifiesta en el período perinatal como distress respiratorio. Sin embargo, esta malformación puede ser detectada con menor frecuencia en la adolescencia y la adultez, asociada a infecciones pulmonares recurrentes o como hallazgo incidental en imágenes. El reconocimiento de las características imaginológicas de esta lesión permite hacer un diagnóstico preciso y óptimo manejo. Se debe sospechar la presencia de MAQ en adultos con tos persistente recurrente asociada a una masa quística multiloculada con niveles hidroaéreos, comprometiendo un lóbulo pulmonar y con vasculatura normal al AngioTC. Con el uso de técnicas de imágenes más sensibles durante el embarazo y la infancia, el diagnóstico tardío de esta patología será cada vez menos frecuente.

\section{Bibliografía}

1. Lujan M, Bosque M, Mirapeix RM, Marco MT, Asensio O, Domingo C. Late-Onset Congenital Cystic Adenomatoid Malformation of the Lung. Respiration 2002; 69: 148-154.

2. Kim W, Lee K, Kim IO, Suh YL, Im JG, Yeon KM et al. Congenital Cystic Adenomatoid Malformation of the Lung: CT-Pathologic Correlation. AJR 1997; 168: 47-53.

3. Hulnick D, Naidich D, McCauley D, Feiner $H$, Avitabile A, Greco M, Genieser N. Late Presentation of Congenital Cystic Adenomatoid Malformation of the Lung. Radiology 1984; 151: 569-573.

4. Fibla JJ, Molins L, Mier JM. Malformación adenomatoidea quística pulmonar de afectación bilateral en el adulto. Arch Bronconeumol 2008; 44(4): 226-7.

5. Congregado M, Loscertales J, Girón-Arjona JC, JiménezMerchán R, Arroyo-Tristán A, González Cámpora $R$. Tres casos de malformación adenomatoidea quística en el adulto tratados por cirugía videotoracoscópica. Arch Bronconeumol 2004; 40(5): 236-239.

6. Mata J, Cáceres J, Lucaya J, García-Conesa J. CT of Congenital Malformations of the Lung. Radiographics 1990; 10: 651-674.

7. Oh BJ, Lee JS, Kim S, Lim M, Koh Y. Congenital cystic adenomatoid malformation of the lung in adults: Clinical and CT evaluation of seven patients. Respirology 2006; 11: 496-501.

8. Rosado M, Stoker J. From the Archives of the AFIP. Congenital Cystic Adenomatoid Malformation. Radiographics 1991; 11: 865-886.

9. loachimescu $C$, Mehta $C$. From cystic pulmonary airway malformation, to bronchioloalveolar carcinoma and adenocarcinoma of the lung. Eur Respir J 2005; 26: 1181-1187.

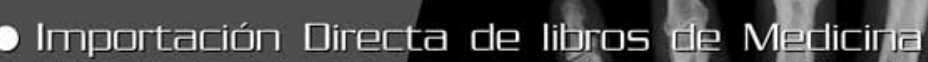

Rapidez, seriedad y puntualidad en entuega de textos

Servicio integral de calidad

Atencián Persanalizada.

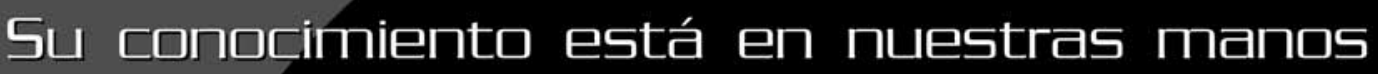

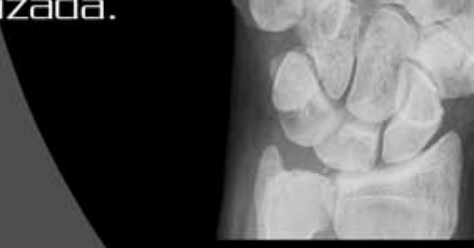

Solicite a пuestro representante para toda el país

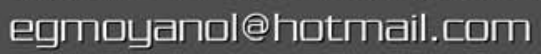

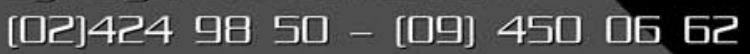

General Medicine Boaks - Manseñor Eyzaguirre \#182

Ñuก̃ロa - 5antiag口 